\title{
Synthesis Procedures for Silver Nanoparticles
}

\section{Cliff Orori Mosiori}

PhD Student, Department of Physics, School of Pure and Applied Sciences, Kenyatta University, Box 43844-00100, KENYA

*Corresponding Contact:

Email: cliffmosiori@ gmail.com

Cell Phone: 0716633719

\begin{abstract}
This article gives some proposals on how to grow silver nanoparticles using different methods. Dilute silver salts are recommended as the metal precursor starting solutions. The formation of the silver nanoparticles is to be monitored using UV-Vis absorption spectroscopy so as to reveal the formation of silver nanoparticles and how they will exhibit surface plasmon absorption maxima at $418-420 \mathrm{~nm}$ from the UV-Vis spectrum. The Mie light scattering theory will be applied and the experimental results analyzed to show the diameter of silver nanoparticles in colloidal solution. Energy-dispersive spectroscopy (EDX), X-ray diffraction (XRD), transmission electron microscopy (TEM) and UV-Vis spectroscopy are proposed to be used to characterize the formed silver nanoparticles obtained. The energy-dispersive spectroscopy (EDX) of the nanoparticles dispersion will confirm the presence or absence of elemental silver signal peaks. The size and morphology of the formed silver nanoparticles will be determined by transmission electron microscopy. The synthesized silver nanoparticles will be structurally characterized by using X-ray diffraction and transmission high-energy electron diffraction (HEED) and the peaks in the XRD pattern will be compared to the standard values of the face-centeredcubic form of metallic silver (ICCD-JCPDS card no. 4-0787).
\end{abstract}

Keywords: Silver Nanoparticles, Surface Plasmon, UV-Vis Absorption Spectrum, Chemical Bath Technique, reverse micelles process, salt reduction, microwave dielectric heating reduction, ultrasonic irradiation, radiolysis, solvo-thermal synthesis, electrochemical synthesis

\section{INTRODUCTION}

As development of nanotechnology applications advance, silver nanoparticles have found many applications in both optical and electronic applications. This is because of their unique size-dependent optical, electrical and magnetic properties. Everywhere, silver nanoparticles have found applications in biotechnology, bioengineering, silver-based and consumer products. They have also been used as the cathode in a silver-oxide battery. This is because modern technology utilizes change of the size, shape, surface and aggregation state of the silver nanoparticles after integration into a target application is critical for optimizing application performance. Many noble metal nanoparticles have been investigated. This is based on their unique electronic, optical, mechanical, magnetic and chemical properties. These unique properties are the ones attributed to their small sizes and large surface area and that is 
why metallic nanoparticles find uses in many applications in deferent fields of electronics and photonics. Different types of preparation methods have been tried and also used to prepare metallic nanoparticles. These methods include reverse micelles process, salt reduction, microwave dielectric heating reduction, ultrasonic irradiation, radiolysis, solvo-thermal synthesis and electrochemical synthesis.

Mono-dispersible silver nanoparticles are ideal in research and development. They are used in a variety of innovative applications. Some companies like Aldrich Materials Science prepare several silver nanoparticles suspension in a dilute aqueous citrate buffer. Silver nanoparticles are incorporated into a wide array of consumer products. These products utilize their desirable optical and conductive properties hence they are used in bio-sensing, efficiently light harvesting and for enhanced optical spectroscopy's including metal-enhanced fluorescence (MEF) and surface-enhanced Raman scattering (SERS).

Silver nanoparticles are used as antibacterial agent though this is relatively new because of their high reactivity due to the large surface to volume ratio. Silver containing materials can be employed to eliminate microorganisms on textile fabrics or they can be used for water treatment.

The simplest bulk-solution synthetic method used to prepare metal nanoparticles is the chemical reduction of metal salts and through this method; nano-sized metal silver particles with different morphologies and sizes have been reported. This synthetic method involves reduction of anionic salt in an appropriate medium in the presence of surfactant using various reducing agents and the dispersions of the nanoparticles display intense colors due to their plasmon resonance absorption. Through the surface of a metal which looks like a plasma, has free electrons in the conduction band and positively charged nuclei. Thus surface Plasmon resonance is therefore a collective excitation of the electrons in the conduction band and near the surface of the nanoparticles where electrons are limited to specific vibrations modes by the particle's size and shape. Therefore, metallic nanoparticles have characteristic optical absorption spectrums in the UV-Vis region which will be investigated.

\section{EXPERIMENTAL}

\section{A. Material and Chemicals}

Silver nitrate $\left(\mathrm{AgNO}_{3}\right)$, Hydrazine hydrate, sodium Citrate and Sodium Dodecyl Sulphate, Double-distilled deionised water, Potassium chloride $(\mathrm{KCl})$, zinc nitrate $\left(\mathrm{Zn}\left(\mathrm{NO}_{3}\right)_{2} \cdot 6 \mathrm{H}_{2} \mathrm{O}\right.$, copper sulfate $\left(\mathrm{CuSO}_{4} .5 \mathrm{H}_{2} \mathrm{O}\right)$, absolute ethyl alcohol $\left(\mathrm{CH}_{3} \mathrm{CH}_{2} \mathrm{OH}\right)$, ethylene glycol (AR), sodium hydroxide $(\mathrm{NaOH})$, sodium boro hydride $\left(\mathrm{NaBH}_{4}\right)$, ascorbic acid $\left(\mathrm{C}_{6} \mathrm{H}_{8} \mathrm{O}_{6}\right)$, trisodium citrate $\left(\mathrm{C}_{6} \mathrm{H}_{5} \mathrm{Na}_{3} \mathrm{O}_{7} .2 \mathrm{H}_{2} \mathrm{O}\right)$, ammonia( $\left.\mathrm{NH}_{3}\right)$, poly vinyl alcohol ( PVA).

\section{B1. Preparation of silver nanoparticles}

Sodium Dodecyl Sulphate (SDS) and Citrate of sodium were used. Silver nitrate solution (ranging from $1.0 \mathrm{mM}$ to $5.0 \mathrm{mM}$ ) and Sodium Dodecyl Sulphate of concentration of $8 \%$ $\mathrm{w} / \mathrm{w}$ ) will be used as a metal saltprecursor and a stabilizing agent, respectively. Hydrazine hydrate solution with a concentrate ranging from $1.00 \mathrm{mM}$ to $1.2 \mathrm{mM}$ and Citrate of sodium solution $(1.0 \mathrm{mM}$ to $2.0 \mathrm{mM})$ will be used as a reducing and stabilizing agents. The silver nanoparticles will be purified by centrifugation and to remove excess silver ions, the silver colloids will be washed at least three times with deionized water under nitrogen stream. A dried powder of thenano-size silver is expected to be obtained by freeze-drying. 


\section{B2. Synthesis of Ag nanoparticles using tri sodium citrate as a reducing agent}

Silver nitrate and trisodium citrate will be used as starting materials. Silver colloid will be prepared using chemical reduction method where all solutions of reacting materials will be prepared using distilled water. $5.0 \mathrm{ml}$ of $0.001 \mathrm{M} \mathrm{AgNO}_{3}$ was heated to boil; $5 \mathrm{~mL}$ of $1 \%$ trisodium citrate will be added drop by drop. It will be removed from the heating device and stirred until cooled to roomtemperature.0.002 $\mathrm{M}$ silver nitrate and $0.02 \mathrm{M}$ trisodium citrate will be added.

\section{B3. Synthesis of Ag nanoparticles using sodium boro hydride as a reducing agent}

$30 \mathrm{~mL}$ of $0.002 \mathrm{M}$ sodium boro hydride solution will be chilled in an ice bath and different volumes of $0.001 \mathrm{M}$ silver nitrate will be added slowly drop wise. The reaction mixture will be stirred vigorously using a magnetic stirrer and the entire addition process take about 3 minutes, after which the stirring will be stopped and the stirrer bar was removed.

\section{B4. Preparation of Ag-nanoparticles using aniline}

Silver nanoparticles will be prepared through silver nitrate solution using aniline in presence of CTAB. $8 \mathrm{ml}$ of a $0.01 \mathrm{~mol} \mathrm{dm}^{-3}$ solution of silver nitrate will be mixed with $5 \mathrm{ml}$ of a $0.01 \mathrm{~mol} \mathrm{dm}^{-3} \mathrm{CTAB}$ solution. $20 \mathrm{ml}$ of a $0.01 \mathrm{~mol} \mathrm{dm}^{-3}$ solution of aniline will be added to the solution of silver nitrate and $\mathrm{CTAB}$. The total volume of the reaction mixture will be maintained at $50 \mathrm{ml}$ and a $\mathrm{pH}$ of 10.2 .

\section{B5. Preparation of Ag-nanoparticles using aniline}

The silver sol will be prepared by reduction of $\mathrm{Ag}^{+}$ions using addition of ethyl alcohol containing $2 \%$ PVP solution with weight ratios of $\mathrm{AgNO}_{3}$ metal salt to PVP being 1:5. The glass rod will besonicated in a sonic bath and the prepared suspension will be applied to a polyethylene substrates manually using controlled wire-wound rod. The Ag film looks very uniform over the entire substrate. The same procedure will be followed to prepare silver sol for synthesize nano-film on glass substrate that previously was immersed in the sol of as prepared coating material at a constant uniform speed. After 24 hours substrate will be pulled up with same uniform speed.

\section{Characterization techniques}

Ultraviolet-visible Spectroscopy (UV-Vis) will be performed in a spectrophotometer. Size, morphology and composition of the nanoparticles will be performed using transmission electron microscopy (TEM), energy dispersive X-ray Analysis (EDX) and high energy electron diffraction (HEED) using a microscope. Histograms of size distribution will be calculated from the TEM images by measuring the diameters of at least 50 particles. Samples for TEM studies will be prepared by placing drops of the silver nanoparticles solutions on carbon-coated TEM grids.

\section{REFERENCES}

For 2003 International Technology Roadmap for Semiconductors (ITRS), see website http://public.itrs.net/.

G. Stix, Little big Science, Scientific American Sept. 2001, p.32, and the articles following this one.

G. Timp (ed.), Nanotechnology (Springer, New York, 1999).

G.A. Ozin, A.C. Arsenault, Nanochemistry: A chemical approach to nanomaterials (RSC Publishing, 2005).

H.-S.P. Wong, D.J. Frank, P.M. Solomon, C.H.J. Wann, J.J. Welser, Nanoscale CMOS, Proc. IEEE 87, 537 (1999).

Hari Singh Nalwa (ed.), Nanostructured materials and nanotechnology (Academic Press, London, 2002). 
J. Birnbaum, R.S. Williams, Physics and the information revolution, Phys.Today Jan. 2000, p.38.

M.S. Dresselhaus, I.L. Thomas, Alternative energy technologies, Nature414, 332 (2001).

P. Moriarty, Nanostructured materials, Rep. Prog. Phys.64, 297 (2001).

P.M. Solomon, Device innovation and material challenges at the limits of CMOS technology, Annu. Rev. Mater. Sci.30, 681 (2000).

R. Compañó, L. Molenkamp, D.J. Paul, Technology Roadmap for Nanoelectronics, http://nanoworld.org/NanoLibrary/nanoroad.pdf.

R.P. Feynman, in H.D. Gilbert (ed.), Miniaturization (Reinhold, New York, 1961), pp. 282-296.

R.W. Keyes, Fundamental limits of silicon technology, Proc. IEEE 89, 227 (2001).

The Royal Society, Nanoscience and nanotechnologies: opportunities and uncertainties, http://www.nanotec.org.uk/ finalReport.htm (July 2004).

Y. Tauret al., CMOS scaling into the nanometer regime, Proc. IEEE 85, 486 (1997). 